Available online on 15.05.2020 at http://jddtonline.info
Open Access to Pharmaceutical and Medical Research
unrestricted non-commercial use, provided the original work is properly cited

Open $\odot$ Access

Research Article

\title{
Effect of Granulation Methods on Drug Release Studies in Sustained Release Matrix Tablets of a Poorly Soluble Drug prepared using Synthetic Polymers
}

\author{
Ayalasomayajula Lakshmi Usha*, E. Radha Rani' ${ }^{1}$ A.V.S. Ksheera Bhavani², A. Vyasa Murty ${ }^{3}$ \\ 1. Department of Pharmaceutics, Maharajah's College of Pharmacy, Vizianagaram, A.P., India \\ 2. Department of Pharmaceutics, Sri Venkateswara College of Pharmacy, Etcherla, Srikakulam, A.P., India \\ 3. Department of Pharmaceutical Sciences,Univesity of Tasmania, Hobart, Australia
}

\begin{abstract}
Vomiting or emesis is the abnormal emptying of stomach and upper part of intestine through esophagus and mouth. It occurs due to stimulation of the emetic (vomiting) centre situated in the medulla oblongata. Domperidone, a $\mathrm{D}_{2}$ receptor antagonist has antiemetic and prokinetic action is used as a model drug in the present work to prepare Sustained release matrix tablets using various synthetic polymers like Eudragit and HPMC K15 M. The tablets are designed to have a pH dependent release profile in order to prevent initial drug release in the stomach to reduce the possible gastro-irritant and ulcerogenic effects of the drug. Different polymer and diluent concentrations and various compression techniques like wet granulation technique and direct compression techniques were used in order to release the contents of the tablets in a sustained manner over a certain period of time. Domperidone is BCS Class II drug and its solubility was enhanced by preparing solid dispersions using solvent evaporation technique. In the present work solid dispersions containing drug and polymer mixture in the ratio $1: 1$ was further formulated into tablets by incorporating various synthetic polymers in three different concentrations. The tablets were prepared using different granulating techniques. Formulation (F3) containing drug and polymers in the ratio 1:1 prepared by wet granulation technique could sustain the drug release over a period of $12 \mathrm{~h}$ and hence considering all the post compression parameters it was optimized as the better formulation. FTIR, DSC, X-Ray Diffraction, SEM studies were performed for optimized solid dispersion mixture and also the optimized formulation.
\end{abstract}

Keywords: Solubility enhancement, Solid dispersions, Solvent Evaporation, Wet granulation, Direct Compression.

Article Info: Received 19 March 2020; Review Completed 22 April 2020; Accepted 28 April 2020; Available online 15 May 2020

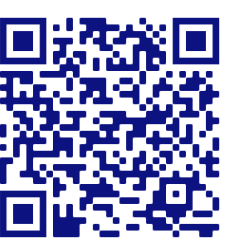

Cite this article as:

Ayalasomayajula LU, Radha Rani E, Ksheera Bhavani AVS, Vyasa Murty A, Effect of Granulation Methods on Drug Release Studies in Sustained Release Matrix Tablets of a Poorly Soluble Drug prepared using Synthetic Polymers, Journal of Drug Delivery and Therapeutics. 2020; 10(3):76-82 http://dx.doi.org/10.22270/jddt.v10i3.4073

Lakshmi Usha Ayalasomayajula, Department of Pharmaceutics, Maharajah's College of Pharmacy. Vizianagaram, AP, India

\section{INTRODUCTION:}

Oral drug delivery has been the most widely preferred route of administration among all the routes for the systemic delivery of drugs from various pharmaceutical products or different dosage forms. Nowadays most of the pharmaceutical scientists are involved in developing ideal Drug Delivery Systems. This ideal system should have an advantage that a single dose should deliver the drug directly at specific site for whole duration of the treatment. The aim in designing sustained delivery systems is to reduce the frequency of the dosing and to increase effectiveness of the drug by localization at the site of action. [1]

There has been a profound increase in the development of sustained release drug delivery system in the last two decades due to various reasons like expiration of various international patents, prohibitive cost of developing new drug entities, discovery of new polymeric materials that are suitable for retarding the release of the drug, improvement in therapeutic efficiency and safety [2]. Of all sustained release dosage forms, matrix tablets are considered to be the commercially feasible dosage forms that involve the least processing variables, utilize the conventional facilities and accommodate large doses of drug. Matrix devices had gained steady popularity in pharmaceutical research due to their chemical inertness, drug embedding ability and drug release character [3].

Vomiting is regulated centrally by the vomiting centre and the chemoreceptor trigger zone (CTZ), which are present in the medulla. The CTZ is sensitive to chemical stimuli and is the main site of action of many emetic and antiemetic drugs. Dopamine (acting through D2 receptors) is an inhibitory transmitter in the GIT normally acts to delay gastric emptying when food is present in stomach. It also appears to 
cause gastric dilation and LES relaxation attending nausea and vomiting [4]. Domperidone blocks D2 receptors and has an opposite effect-hastening gastric emptying and enhancing LES tone by augmenting Ach release, clinically this action is exerted through 5HT receptors. The central anti dopamergic action on CTZ responsible for anti-emetic property [5]

The main aim of the present work is to formulate and evaluate sustained release matrix tablets of Domperidone by using natural polymers like Eudragit RS 100 and HPMC K15M using various compression techniques like wet granulation technique and direct compression techniques.

\section{MATERIALS AND METHODS:}

\section{Materials:}

Domperidone, Eudragit RS 100, and Hydroxyl propyl methyl cellulose K15M, $B$ cyclodextriene and Lacctose were obtained from Yarrow chem products, Mumbai. Talc was obtained from Otto Chemika Biochemika reagents.

\section{Method:}

Domperidone a BCS class II drug is poorly soluble in water. Therefore, solubility of Domperidone was enhanced by preparing solid dispersions using solvent evaporation technique. Solvent evaporated mixtures were formulated by using drug and carrier in different ratios such as 1:0.75, 1:1 1:1.5. Dissolution studies were performed for the solvent evaporated mixtures using USP dissolution type II apparatus (paddle method) at $50 \mathrm{rpm}$ using $6.8 \mathrm{pH}$ phosphate buffer as dissolution medium at $37 \pm 0.5^{\circ} \mathrm{C}$. Based on physicochemical characterization, solvent evaporated mixture containing drug and carrier in the ratio of $1: 1$ (equivalent to $30 \mathrm{mg}$ of drug) was selected to formulate into sustain release tablets.

Table 1: Formulation table for Solid Dispersions

\begin{tabular}{|c|c|c|c|}
\hline Formulation code & Carriers & Method & Drug: Polymer ratio \\
\hline SD 1 & HP- $\beta$-CD & Solvent evaporation & $1: 0.75$ \\
\hline SD 2 & HP- $\beta$-CD & Solvent evaporation & $1: 1$ \\
\hline SD 3 & HP- $\beta$-CD & Solvent evaporation & $1: 1.5$ \\
\hline
\end{tabular}

Sustained release matrix tablets of Domperidone were prepared by using direct compression technique and wet granulation techniques. The optimized mixtures were characterized by FTIR spectroscopy, DSC studies, X-ray diffraction etc.

Table 2: Formulation table for Preparation of tablets:

\begin{tabular}{|l|l|l|l|l|l|l|l|l|l|l|l|l|l|l|}
\hline Ingredients & F1 & F2 & F3 & F4 & F5 & F6 & F7 & F8 & F9 & F10 & F11 & F12 \\
\hline Method & \multicolumn{7}{|c|}{ Wet Granulation Method } \\
\hline Domperidone & 30 & 30 & 30 & 30 & 30 & 30 & 30 & 30 & 30 & 30 & 30 & 30 \\
\hline HPMC K15 M & 7.5 & 15 & 30 & - & - & - & 7.5 & 15 & 30 & - & - & - \\
\hline Eudragit RS100 & - & - & - & 7.5 & 15 & 30 & - & - & - & 7.5 & 15 & 30 \\
\hline Lactose & 158 & 150 & -- & 158 & 150 & 135.5 & 158 & 150 & 135.5 & 158 & 150 & 135.5 \\
\hline Mg Stearate & 3 & 3 & 3 & 3 & 3 & 3 & 3 & 3 & 3 & 3 & 3 & 3 \\
\hline Talc & 1.5 & 1.5 & 1.5 & 1.5 & 1.5 & 1.5 & 1.5 & 1.5 & 1.5 & 1.5 & 1.5 & 1.5 \\
\hline
\end{tabular}

Direct Compression Technique: All the ingredients were weighed separately dried for 30 mins at $50^{\circ} \mathrm{C}$ and cooled to room temperature. They were then passed through \#40 sieve separately to attain fine powder. The sieved powders were weighed and added geometrically (except glidant and lubricant), mixed properly and then finally lubricant and talc were added just before compression. This mixture was directly compressed using rotary tablet punching machine equipped with $8 \mathrm{~mm}$ flat faced circular punches at a constant compression force.[6]

Wet Granulation Technique: In this technique all the ingredients except lubricants and anti- adherent were mixed properly and then the mixture is formed into dough using $2 \%$ starch paste as a binding agent. Then the dough is then passed through the sieve \#22 to form the granules. The so formed granules were dried at $50^{\circ} \mathrm{C}$ and then cooled at room temperature. Lubricant and glidant were added. Then the mixture was compressed using rotary tablet punching machine equipped with $8 \mathrm{~mm}$ flat faced circular punches at a constant compression force.[7]

\section{Evaluation Parameters:}

\section{Pre Compression Parameters:}

Prior to the compression of tablets, the blend of drug and excipients of all the batches were evaluated for various micromeritic properties like Angle of repose, bulk density, tapped density, Carr's Compressibility index and Hausner's ratio.[8]

\section{Post Compression Parameters:}

Thickness: Thickness of the sustained release tablets were tested using calibrated Vernier-calipers. The tablet thickness was controlled within a $\pm 5 \%$ variation.

Hardness test or crushing strength:Hardness is the force required to break a tablet across the diameter. It is measured in kilograms and a crushing strength of usually $4 \mathrm{~kg}$ is considered to be the minimum satisfactory for tablets. The hardness was tested using Monsanto hardness tester.

Friability test: This is an in process quality control test performed to ensure the ability of tablets to withstand shocks during processing, handling, transportation, and 
shipment. It is usually measured by using Roche Friabilator.[9]

$$
\% \text { friability }=\frac{\text { Weight }_{\text {initial }}-\text { Weight }_{\text {final }}}{\text { Weight }_{\text {initial }}} \times 100
$$

Uniformity of weight or Weight variation test: This test is performed to check the weight of the tablet frequently (every half an hour) so that in case of any corrections will be made during the compression of tablets. Any variation in the weight of the tablet may lead to over dose or under dose of medication. Therefore every tablet in each batch should have a uniform weight.[10]

$\%$ deviation $=[$ (individual weight-average weight $)]$ /average weight $\times 100$

Estimation of drug content: Drug content was determined accurately by weighing 5 tablets and crushing them in motor with the help of a pestle. Content uniformity was calculated using the following formula.

$$
\% \text { purity }=10 \mathrm{C}(\mathrm{Au} / \mathrm{As})
$$

Where, $\mathrm{C}=$ Concentration, $\mathrm{Au}$ and $\mathrm{As}=$ absorbance obtained from the standard preparation and assay preparation respectively.

\section{In-vitro drug release studies:}

The dissolution behaviour of Domperidone was recorded using a dissolution apparatus (Disso 2000 LAB INDIA, Mumbai). USP dissolution apparatus with rotating paddle assembly (type II) was used at $50 \mathrm{rpm}$, in $900 \mathrm{ml}$ of deionised water (phosphate buffer $\mathrm{pH}$ 6.8). The mean of the three determinations was used to calculate the drug release from the tablets. The samples were withdrawn at predetermined time intervals, and equal amount of fresh buffer was replaced. The obtained samples were filtered and assayed spectrophotometrically at $285 \mathrm{~nm}$.[11]

\section{FT-IR Study:}

The FT-IR spectra of pure drug, polymers and optimized formulation were scanned over a frequency range 4000-400 $\mathrm{cm}-1$ by placing sample on diamond ATR and analyzing for the presence of characteristic peaks.[12]

\section{Thermal Analysis:}

DSC was performed using DSC calorimeter to study the thermal behavior of pure drug, polymers and mixture of optimized formulation. The required amounts of samples were heated in sealed aluminium pans under nitrogen flow $(30 \mathrm{ml} / \mathrm{min})$ at a scanning rate $5^{\circ} \mathrm{C}$ per min from $40^{\circ} \mathrm{C}$ to $250^{\circ} \mathrm{C}$. The heat flow as a function of temperature and enthalpy change was measured for the drug, polymers and mixture of optimised formulation. [13]

\section{$X$-ray diffraction analysis:}

X-ray diffraction is an important tool to investigate the crystal structure as well as the average structural spacing between the layers or rows of atoms in an unknown material. Formulations were subjected to X-ray diffraction analysis, using $\mathrm{Cu}$ target slit $10 \mathrm{~mm}$ to investigate the physical state of Domperidone, HP- $\beta-C D$ and Domperidone solvent evaporated mixtures.[14]

\section{Scanning Electron Microscopy:}

Scanning electron microscope (SEM) allows viewing and surface analysis of solid dispersions as well as spatial pattern formation for the scanned object. This is very important for the qualitative assessment of their properties such as particle size, their shape, morphology, porosity, presence of crystalline forms, as well as tested powders texture monitoring.[15]

\section{RESULTS}

\section{Characterization of pure drug Domperidone:}

Identification of Domperidone by UV- visible spectrophotometer: Standard plot of Domperidone was constructed by taking series of concentration in $\mathrm{pH} 6.8$ phosphate buffer and $\mathrm{pH} 1.2 \mathrm{~N} \mathrm{HCl}$ buffer. The absorption spectra were recorded in the wavelength region of 200-400 $\mathrm{nm}$ in the UV visible spectrophotometer. The absorption maximum of Domperidone was found to be $285 \mathrm{~nm}$.

Melting point: Melting point of Domperidone was determined using melting point apparatus and DSC. The temperature at which the drug starts to melts is recorded and compared to its standard value. Melting point of Domperidone was found to be $245.98^{\circ} \mathrm{C}$ by DSC and 242$246^{\circ} \mathrm{C}$ by melting method, which complies with the standard values in the official monograph as per USP- NF. The above determined results show the drug is pure and free from impurities.[16]

Solubility: Solubility determination of Domperidone was carried out in water and organic solvents. As it is class II drug, Domperidone shows poor solubility. It was found that Domperidone is practically insoluble in water, but soluble in organic solvents like ethanol, dimethylsulfoxide. The above estimation done was beneficial for further studies.[17]

\section{Compatibility studies of solid dispersions:}

Visual inspection: Visual inspections were conducted to check the compatibility between drug and excipients in its physical mixture when stored in glass container at room temperature for a certain period of time. The main objective of this inspection was to observe any colour change in the physical mixture. Throughout the examination, there was no change in the colour of the physical mixture throughout the examination period, indicating that drug and excipients are quite compatible each other.

FTIR (Fourier transformer infrared spectroscopy): The physical mixture of drug and excipients was characterized by FTIR spectrum by yris Diamond TG/ DTA. The FTIR of the pure drug and solid dispersion did not show any peak indicating the absence of any chemical reaction between Domperidone and $\beta$-cyclodextrin

DSC (Differential scanning Calorimetry): DSC thermogram of Domperidone showed a sharp peak at due to the melting point of the drug and indicating its crystalline nature. This shows that the drug considered for the research is in pure form. The measured melting endotherm of the $\beta$ cyclodextrin is $91.27^{\circ} \mathrm{C}$.

XRD (X-ray diffraction): The X-ray diffractograms of Domperidone showed characteristics sharp intensity diffraction peaks at $27.353^{\circ} \mathrm{C}$

\section{Determination of drug content and percent yield in solid dispersions:}

All the solid dispersions prepared by solvent evaporation method were in the form of free flowing powders. The values of $\%$ drug content and $\%$ yield values were determined.

In-Vitro Dissolution Studies of SD'S: The in vitro dissolution studies were performed for the solid dispersions. The drug release from solid dispersions was 72.8, 97.53, and $85.51 \%$ respectively in $1 \mathrm{hr}$. 
Table 3: In vitro dissolution profile for solid dispersions

\begin{tabular}{|l|l|l|l|}
\hline Time (mins) & \multicolumn{1}{|c|}{ SD 1 } & \multicolumn{1}{|c|}{ SD 2 } & SD 3 \\
\hline 5 & $33.69 \pm 1.534$ & $45.68 \pm 2.92$ & $35.4 \pm 1.98$ \\
\hline 10 & $42.31 \pm 2.630$ & $55.35 \pm 1.31$ & $49.9 \pm 2.41$ \\
\hline 15 & $50.49 \pm 0.75$ & $63.21 \pm 3.0$ & $54.32 \pm 3.06$ \\
\hline 30 & $56.36 \pm 1.26$ & $79.58 \pm 3.92$ & $67.49 \pm 2.91$ \\
\hline 45 & $65.39 \pm 1.06$ & $88.48 \pm 3.40$ & $72.51 \pm 2.41$ \\
\hline 60 & $72.8 \pm 2.08$ & $\mathbf{9 7 . 5 3} \pm \mathbf{3 . 1 6}$ & $85.51 \pm 3.57$ \\
\hline
\end{tabular}

From the above data Solid dispersion SD2 was optimized as the best formulation and was further compressed into tablets.

\section{Precompression Parameters}

Precompression studies are conducted in order to determine the flow-ability, compressibility studies of the powder blend and granules.
Different tablet batch formulations F1-F6 were prepared by wet granulation and F7-F12 by direct compression methods. Solid dispersion mixture (75mg) and other all excipients were passed individually through \#40 sieve and mixed well for $10 \mathrm{~min}$ in a mortar and pestle to form a powder blend. This blend was compressed into tablets by wet granulation and direct compression techniques using single punch rotary tablet punching machine using $8 \mathrm{~mm}$ flat punches.

Table 4: Post compression parameters of various formulations prepared by Wet granulation and Direct Compression Techniques

\begin{tabular}{|c|c|c|c|c|c|}
\hline $\begin{array}{l}\text { Formulation } \\
\text { code }\end{array}$ & $\begin{array}{l}\text { Thickness } \\
\text { (mm) }\end{array}$ & $\begin{array}{l}\text { Weight variation } \\
\text { (mg) }\end{array}$ & $\begin{array}{l}\text { Hardness } \\
\left(\mathrm{kg} / \mathrm{cm}^{2}\right)\end{array}$ & Friability (\%) & Drug content (\%) \\
\hline F1 & $5.5 \pm 2.39$ & $203.4 \pm 2.51$ & $6.5 \pm 2.05$ & $0.78 \pm 2.54$ & $98.56 \pm 2.18$ \\
\hline F2 & $5.2 \pm 2.45$ & $201.5 \pm 2.26$ & $7.5 \pm 2.40$ & $0.61 \pm 2.54$ & $99.56 \pm 2.11$ \\
\hline F3 & $5.3 \pm 2.30$ & $195.5 \pm 2.54$ & $8 \pm 2.51$ & $0.65 \pm 2.11$ & $98.45 \pm 2.14$ \\
\hline F4 & $5.4 \pm 2.12$ & $199.5 \pm 2.51$ & $8.5 \pm 2.25$ & $0.83 \pm 2.04$ & $99.05 \pm 2.16$ \\
\hline F5 & $5.6 \pm 2.19$ & $204.5 \pm 2.45$ & $7.5 \pm 2.39$ & $0.64 \pm 2.18$ & $97.52 \pm 2.15$ \\
\hline F6 & $5.5 \pm 2.12$ & $200 \pm 2.54$ & $6.5 \pm 2.29$ & $0.65 \pm 2.31$ & $98.54 \pm 2.11$ \\
\hline F7 & $5.5 \pm 2.35$ & $203.4 \pm 2.51$ & $6.5 \pm 2.05$ & $0.68 \pm 2.54$ & $98.36 \pm 2.13$ \\
\hline F8 & $5.2 \pm 2.42$ & $201.5 \pm 2.26$ & $7.5 \pm 2.30$ & $0.61 \pm 2.54$ & $99.96 \pm 2.12$ \\
\hline F9 & $5.3 \pm 2.25$ & $198.5 \pm 2.54$ & $8 \pm 2.21$ & $0.75 \pm 2.11$ & $100.96 \pm 2.15$ \\
\hline F10 & $5.4 \pm 2.18$ & $196.5 \pm 2.51$ & $8.5 \pm 2.20$ & $0.73 \pm 2.04$ & $99.21 \pm 2.25$ \\
\hline F11 & $5.6 \pm 2.14$ & $202.5 \pm 2.45$ & $7.5 \pm 2.21$ & $0.64 \pm 2.12$ & $98.56 \pm 2.26$ \\
\hline F12 & $5.5 \pm 2.12$ & $197.5 \pm 2.54$ & $6.5 \pm 2.29$ & $0.65 \pm 2.41$ & $99.56 \pm 2.25$ \\
\hline
\end{tabular}

\section{In-vitro drug release studies:}

Prepared tablets were evaluated by conventional In-vitro dissolution testing USP type II apparatus at $50 \mathrm{rpm}$. Initially the dissolution studies were out in $900 \mathrm{ml}$ of $0.2 \mathrm{~N} \mathrm{HCl}$ for 2 hours. After the completion of the 2 hours the remaining time period i.e., 10 hours the dissolution studies were performed in $6.8 \mathrm{pH}$ phosphate buffer. Both the media was maintained at the temperature $37 \pm 5^{\circ} \mathrm{C}$. The volume in order to maintain the sink condition; $5 \mathrm{ml}$ of the dissolution media was withdrawn at the predetermined intervals and fresh preheated dissolution media was replaced. 
Table 5: In vitro dissolution profile of Domperidone Sustained release tablets by wet granulation and Direct Compression Techniques.

\begin{tabular}{|c|c|c|c|c|c|c|c|c|c|c|c|c|}
\hline Time & $F 1$ & $F 2$ & F3 & F4 & F5 & F6 & F7 & F8 & F9 & F10 & F11 & F12 \\
\hline & \multicolumn{6}{|c|}{ Wet granulation Technique } & \multicolumn{6}{|c|}{ Direct Compression Technique } \\
\hline 1 & $5.96 \pm 1.4$ & $7.42 \pm 1.2$ & $8.01 \pm 1.9$ & $10.52 \pm 1.3$ & $9.62 \pm 1.5$ & $10.56 \pm 1.2$ & $7.56 \pm 1.2$ & $14.68 \pm 1.5$ & $15.58 \pm 1.2$ & $14.52 \pm 1.2$ & $19.52 \pm 1.2$ & $16.46 \pm 1.2$ \\
\hline 2 & $14.64 \pm 1.2$ & $19.44 \pm 1.5$ & $16.03 \pm 1.2$ & $18.26 \pm 2.3$ & $21.45 \pm 1.6$ & $25.44 \pm 1.3$ & $12.56 \pm 1.3$ & $15.51 \pm 1.6$ & $19.21 \pm 1.3$ & $20.21 \pm 1.3$ & $22.52 \pm 1.6$ & $22.51 \pm 1.3$ \\
\hline 3 & $25.4 \pm 2.1$ & $30.48 \pm 1.3$ & $28.8 \pm 1.3$ & $27.56 \pm 1.4$ & $31.62 \pm 1.4$ & $35.65 \pm 1.4$ & $28.45 \pm 1.3$ & $31.56 \pm 1.2$ & $31.52 \pm 1.4$ & $32.25 \pm 1.4$ & $29.56 \pm 1.4$ & $32.52 \pm 1.3$ \\
\hline 5 & $49.25 \pm 1.7$ & $40.06 \pm 1.6$ & $48.58 \pm 1.7$ & $48.29 \pm 1.6$ & $41.25 \pm 1.3$ & $55.26 \pm 1.3$ & $71.56 \pm 1.2$ & $69.72 \pm 1.5$ & $52.56 \pm 1.5$ & $55.56 \pm 1.4$ & $40.56 \pm 1.5$ & $44.42 \pm 1.4$ \\
\hline 6 & $59.52 \pm 1.3$ & $47.96 \pm 1.3$ & $59.04 \pm 1.6$ & $54.65 \pm 1.5$ & $43.21 \pm 1.6$ & $58.36 \pm 1.3$ & $88.86 \pm 1.5$ & $81.54 \pm 1.3$ & $68.52 \pm 1.4$ & $69.72 \pm 1.6$ & $56.21 \pm 1.3$ & $49.51 \pm 1.3$ \\
\hline 7 & $65.21 \pm 1.6$ & $59.41 \pm 1.4$ & $65.82 \pm 1.5$ & $68.25 \pm 1.7$ & $48.54 \pm 1.6$ & $63.24 \pm 1.6$ & $98.32 \pm 1.8$ & $95.56 \pm 1.5$ & $85.86 \pm 1.5$ & $73.59 \pm 1.8$ & $67.56 \pm 1.5$ & $56.52 \pm 1.2$ \\
\hline 8 & $88.92 \pm 1.5$ & $69.54 \pm 1.4$ & $73.21 \pm 1.4$ & $85.86 \pm 1.5$ & $54.52 \pm 1.2$ & $69.71 \pm 1.6$ & - & - & $96.26 \pm 1.4$ & $85.46 \pm 1.7$ & $73.21 \pm 1.5$ & $61.52 \pm 1.7$ \\
\hline 10 & - & $81.54 \pm 1.3$ & $87.51 \pm 1.1$ & - & $65.66 \pm 1.3$ & $83.52 \pm 1.6$ & - & - & - & - & $94.22 \pm 1.5$ & $71.52 v 1.5$ \\
\hline 11 & - & $92.22 \pm 2.3$ & $91.56 \pm 1.5$ & - & $69.24 \pm 1.5$ & $89.51 \pm 1.3$ & - & - & - & - & - & $75.21 \pm 1.5$ \\
\hline 12 & - & - & $98.26 \pm 1.4$ & - & $73.41 \pm 1.5$ & $93.56 \pm 1.4$ & - & - & - & - & - & $75.21 \pm 1.8$ \\
\hline
\end{tabular}

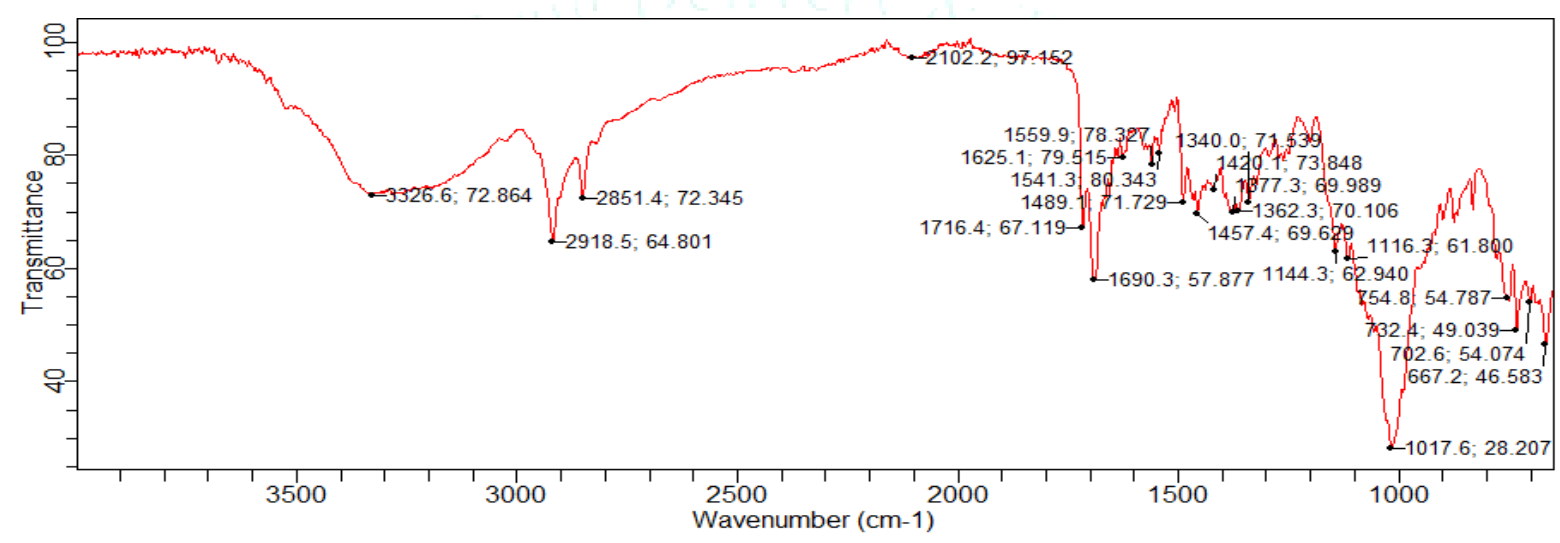

Fig 1: FTIR spectrum of Optimised Formulation

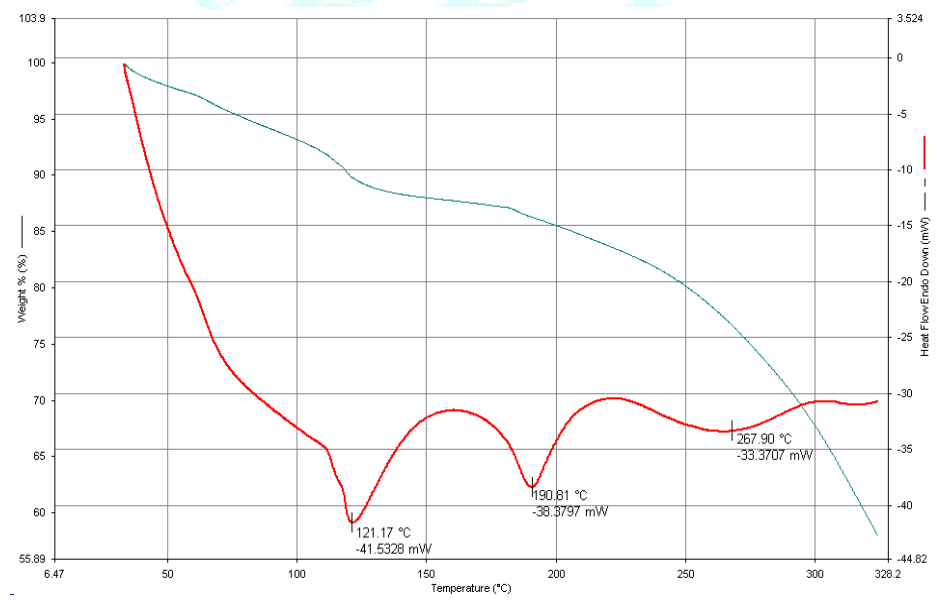

Fig 2: DSC thermo gram of Optimized formulation 


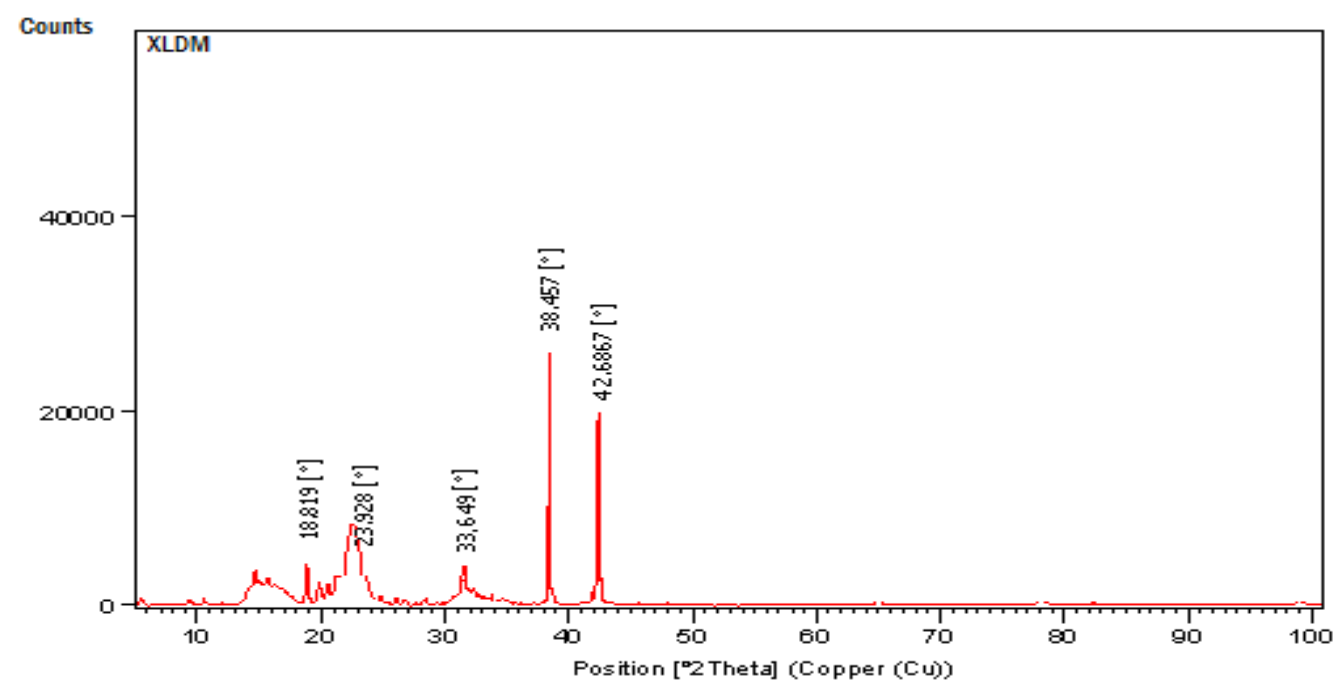

Fig 3: XRD of Optimised formulation

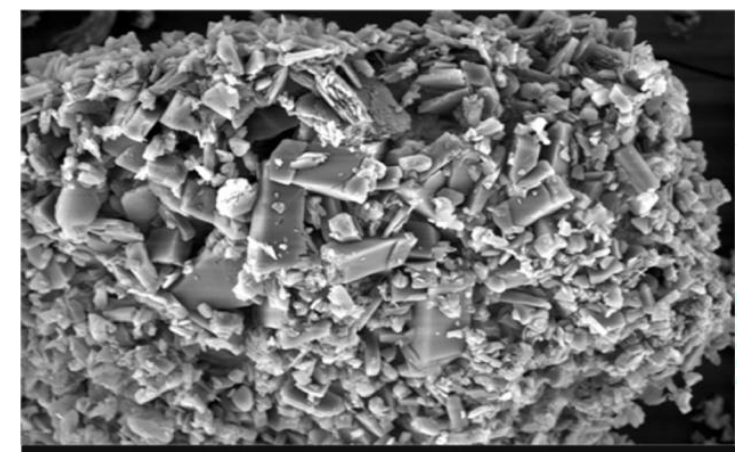

Fig 4: SEM image of Solid Dispersion mixture

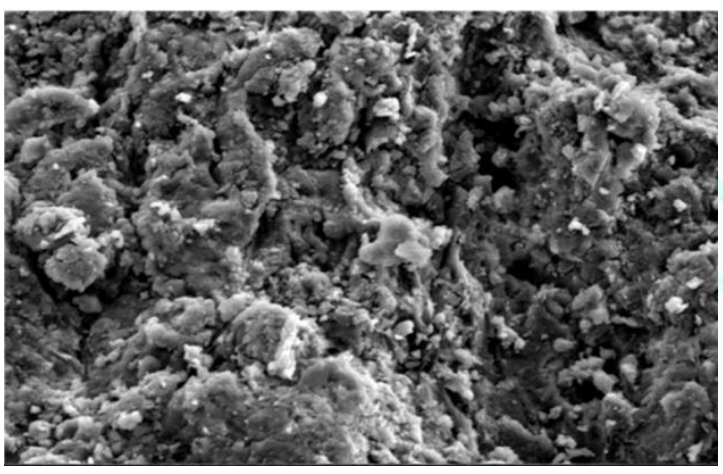

Fig 5: SEM image of optimized drug mixture

\section{DISCUSSION:}

Domperidone is a BCS Class II drug, having less solubility and more permeability. Therefore, the solubility of Domperidone was enhanced by preparing solid dispersions using solvent evaporation technique. $\beta$-cyclodextrin inclusion complexes were prepared in three different ratios like 1:0.75,1:1,1:1.5. In the present work drug:polymer in the ration 1:1 which showed $97 \%$ of drug release in 1 hour was optimized as the best mixture and further formulated into tablets by incorporating synthetic polymers in three different ratios using wet granulation and direct compression techniques.

The active pharmaceutical ingredient Domperidone was evaluated for its physical characteristics and drug polymer compatibility studies. The precompression powder blends of different batches were evaluated for various parameters like angle of repose, bulk density, tapped density, compressibility index Hausner's ratio. The results obtained were found to be satisfactory and within the specified limits.

The matrix tablets were prepared by wet granulation (F1F6) and direct compression (F7-F12) containing different ratios of drug and polymer were subjected to various evaluation tests such as thickness, uniformity of weight, drug content, hardness and friability. The results have complied with the official pharmacopeial limits. It has been observed in this investigation that the formulation (F3) containing drug and HPMC K15M in the ratio 1:1 prepared by wet granulation technique could sustain the drug release over a period of $12 \mathrm{~h}$ and hence considering all the post compression parameters it was optimized as the better formulation.

\section{CONCLUSION:}

Domperidone a BCS class II drug having low solubility and highly permeability was the drug of choice in the present study. It is mainly used in the treatment of Emesis and has a strong affinity for $\mathrm{D}_{2}$ receptors, chemically related to Haloperide, but pharmacologically related to Metaclopramide. Sustained release tablet of Domperidone is preferred because of its prolonged drug release manner, and therefore frequency of the dosing can be reduced.

In the present study, it was decided to design controlled release formulation of Domperidone with $\mathrm{pH}$ dependent release profile so as to prevent initial drug release in the stomach that will reduce the possible gastro-irritant and ulcerogenic effects of the drug. At the same time, there was no compromise on the biopharmaceutical profile of the drug as Domperidone is reported to be well absorbed throughout the GI tract by increasing the half-life eventually producing the sustained action. This gives advantage in reducing the frequency of the dosage to increase effectiveness of the drug by localizing at the site of action.

\section{ACKNOWLEDGMENT}

The authors would like to thank Dr. P. Udaya Shankar, Principal, Maharajah's College of Pharmacy, Vizianagaram, for providing required facilities to carry out this research work. We are also thankful to Mr. Ranjit Prasad Swain, Assistant Professor, Maharajah's College of Pharmacy, Vizianagaram, for his support and encouragement during this work. 


\section{CONFLICTS OF INTEREST}

The authors have no conflicts of interest.

\section{REFERENCES:}

1. Reddymasu SC, Sokyan I, Callum MR W. Domperidone: review of pharmacology and clinical applications in gastroenterology. $\mathrm{Am}$ J Gastroenterol.2007; 102(9):2036-2045.

2. Ratnaparkhi M.P, Gupta Jyothi P. Sustained release Oral drug delivery system- An Overview. International Journal of Pharma Research \& Review, March 2013; 2(3):11-21.

3. Smith HS, Smith EJ, Smith AR. Pathophysiology of nausea and vomiting in palliative medicine. Ann Palliat Med. 2012; 1(1):8793.

4. Andrew PLR, Horn CC. Signals for nausea and vomiting: Implications for model of upper gastrointestinal diseases. Auton Neurosci. 2006: 125(1-2):100-115.

5. Navin D, Sheodutt M, Bhanu PS, Sustained release drug delivery system. Ind J Res Pharma Biotech `2013; 1(3):301-10.

6. Chauhan MJ, Patel SA. A concise review on sustained drug delivery system and its opportunities. Am J Pharmtech Res 2012; 2(2):227-38.

7. Syed IA, Rao YM. A modified release drug delivery device: multilayerd matrix tablets. Am J Pharmtech Res 2012; 2(3):20625.

8. Shanmugam SB, Ayyappan TS, Vetrichelvan T. Formulation and evaluation of sustained release matrix tablet of Zidovudine using different polymers. Res J Pharma Dosage Form Tech 2011; 3(1):17-23.

9. Rahmad MD, Ashan MD, Jha MK, Ahmed I, Rahman MD. Effect of mannitol on release of lamivudine sustained release matrix tablets using methocel $\mathrm{K} 15 \mathrm{M}$ co polymer. Invention Impact \& Pharm Tech 2011; 1:58-62.

10. Madgulkar AR, Bhalekar MR, Warghade NS, Chavan NS. Preparation and evaluation of sustained release matrix tablet of nateglinide - effect of variables. Invention Rapid 2011; 2(1):1419.

11. Jain D, Shukla SB. Formulation and evaluation of sustained release matrix tablets if isoniazid. A comparative aspect based on polymer. Invention Rapid: NDDS 2011; 2(1):14-19

12. Haresh M, Thimmasetty J, Ratan GN. Formulation development and in vitro evaluation of sustained release matrix tablet of risperidone. Invention Impact Pharmatech 2013; 1(1):28-34

13. Chithirra A, Mohamed S, Pillai k, Abirami A, Aruna A Formulation and evaluation of controlled release frusemide tablets by bilayer technology. Journal of drug delivery and research 2013; 3(2):37-44.

14. Sanjay D, Bhaskar M, Sankha C, Das MK, Samrendu S, Ganguly S, Kakali D, Mridula M. Polymers derived from xanthomonas compesteries and retardant materials for the formulation of sustained release floating matrix tablet of atenolol. Int J BioL Macromol 2014; 651:345-56.

15. Praveen S, Ranendra N. Controlled release hydrophilic matrix tablet formulations of isoniazid: design and in vitro studies. AAPS PharmSciTech 2008; 9(4):1171-8.

16. Pranati S, Ranendra N. Formulation and evaluation of paracetamol tablets to access binding property of orange peel pectin. International journal of research and review 2010; (1):30-4.

17. Kamlesh JW, Arvind B, Shailesh A, Milind JU. Formulation and evaluation of sustained release gastroretentive dosage form of metformin Hcl. Der pharmacia letter 2013; 3(1):264-71. 